\title{
Dois empregos ofensivos da expressão castração química: o oponente e o partidário ${ }^{1}$
}

\author{
Deux emplois offensifs de l'expression castration chimique: I'opposant et le partisan \\ Margot Salsmann \\ Centre de Recherches sur les Arts et le Langage (CRAL) - Paris - França
}

\begin{abstract}
Resumo: Este artigo procura compreender de onde vem o poder de causar medo da expressão "castração química", que designa uma técnica médica que visa inibir as pulsões sexuais. Há dois tipos de emprego dessa expressão, cada um sendo, de um ponto de vista retórico, ofensivo a seu modo: o primeiro, o mais antigo, é o dos que se opõem a essa técnica e o segundo é o de seus partidários. Tentaremos determinar por que os oponentes foram os primeiros a empregar essa expressão para ofender seus interlocutores. Nós nos perguntaremos se seu poder ofensivo provém da significação das palavras ou do modo como elas são empregadas. A seguir, procuraremos compreender por que essa expressão é desde então empregada pelos partidários dessa técnica: será que ela não causa mais medo? Sua significação mudou? Ou é o modo como ela é empregada? E por que empregá-la mesmo se ela é considerada inadequada a seu objeto? Conduziremos este trabalho com as ferramentas de análise propostas pela Teoria dos Blocos Semânticos, desenvolvida por Marion Carel e Oswald Ducrot.
\end{abstract}

Palavras-chave: Léxico; Significação; Emprego argumentativo; Retórica; Diacronia

Résumé: Cet article cherche à comprendre d'où vient le pouvoir de faire peur d'une expression à travers l'étude de l'expression "castration chimique", qui désigne une technique médicale visant à inhiber les pulsions sexuelles. Il existe deux types d'emploi de cette expression, chacun étant, d'un point de vue rhétorique, offensif à sa manière: le premier, le plus ancien, est celui des opposants à cette technique et le second est celui de ses partisans. Nous essayerons de déterminer pourquoi les opposants ont, les premiers, employé cette expression pour offenser leurs interlocuteurs, nous nous demanderons si son pouvoir offensif provient de la signification des mots ou de la manière dont ils sont employés? Par suite, nous nous appliquerons à comprendre pourquoi cette expression est désormais employée par les partisans de cette technique: ne faitelle plus peur? Sa signification a-t-elle changé ou est-ce la façon dont elle est employée? Et pourquoi l'employer alors même qu'elle est jugée inadéquate à son objet? Nous mènerons ce travail avec les outils d'analyse que propose la Théorie des Blocs Sémantiques, développée par Marion Carel et Oswald Ducrot.

Mots-clés: Lexique; Signification; Emploi argumentatif; Rhétorique; Diachronie

A técnica médica que consiste em inibir as pulsões sexuais pode ser denominada de dois modos: tratamento hormonal ou castração química. Há alguns anos ainda, escolher, para designar essa técnica, uma dessas expressões mais do que a outra não era inofensiva; bastava empregar a primeira para se mostrar a seu favor, enquanto o emprego da segunda servia para exprimir sua rejeição. Em 2007, quando o presidente Nicolas Sarkozy apresenta seu projeto de lei para a detenção de segurança dos criminosos julgados perigosos, ele enfatiza essa distinção: "Aqueles que aceitarem ser cuidados, poderão ter permissões para sair desse hospital fechado, mas eles o farão usando um bracelete eletrônico e seguindo um tratamento hormonal, chamem-no como quiserem, ou castração química. As palavras não me dão medo. ${ }^{2}$ Dois anos mais tarde, a expressão castração química que visava chocar o interlocutor e que era justamente empregada com esse efeito pelos opositores, está em todas as bocas, inclusive

\footnotetext{
Tradução: Leci Borges Barbisan - PPG Letras - PUCRS.

2 Declaração do Presidente da República, Nicolas Sarkozy, "As medidas de segurança contra os criminosos perigosos", 28 de agosto de 2007, Élysée.fr
} 
nas dos partidários. $\mathrm{O}$ que aconteceu? Essa expressão perdeu seu poder de amedrontar? Se não era esse o caso, como e por que ela é agora utilizada pelos partidários dessa técnica? Desde então se trataria de dar conta do modo como a expressão castração química pode dar lugar a dois empregos ofensivos diferentes: o dos opositores e o dos partidários.

Em uma perspectiva "paralelista" (cf. a tradição referencial), as expressões tratamento hormonal e castração química designam ambas uma mesma técnica: a inibição das funções reprodutivas; no entanto, entendase bem, elas não comunicam a mesma coisa, e elas não têm o mesmo efeito sobre o ouvinte. Tradicionalmente, o sentido de uma expressão linguística é aquele a que ela refere; dito de outro modo, a significação é o que permite identificar o objeto de que se fala. De modo que tratamento hormonal e castração química têm o mesmo sentido, já que elas identificam o mesmo referente - a menos que uma delas seja "falsa", isto é, não adequada para denominar essa técnica médica. Até mesmo se esse argumento é um daqueles que os partidários dessa técnica afirmam contra a de seus oponentes, isso não explica por que a expressão castração química permite mesmo assim aos oponentes designar essa técnica, com violência, e isso explica ainda menos por que ela será utilizada por todos alguns anos mais tarde, enquanto a expressão tratamento hormonal é considerada "verdadeira".

Aceitando-se distinguir, com Frege (1971), entre o sentido e a referência (ou denotação), e considerandose que o sentido é o "modo de doação" do objeto, isto é, o modo como é apresentada a referência, pode-se considerar que até mesmo se as expressões tratamento hormonal e castração química têm a mesma denotação, elas não têm o mesmo sentido, elas não dão a entender a técnica médica do mesmo modo. Eis por que se tratará de determinar o que as diferencia no nível semântico. Para fazer isso, trabalharemos com uma teoria linguística, a saber, a Teoria da Argumentação na Língua e, mais especificamente, a Teoria dos Blocos Semânticos (TBS), desenvolvida por Marion Carel e Oswald Ducrot, que constrói o sentido de uma expressão numa perspectiva "não paralelística", isto é, estabelece a significação das palavras sem colocá-las em relação com os objetos do mundo ou do pensamento que, supõe-se, elas designam.

A Teoria dos Blocos Semânticos concebe a língua como um sistema autônomo de sentido, com sua própria inteligibilidade; a significação de uma palavra não é o modo de doação do referente, mas uma "sequência de palavras, uma "argumentação linguística", pela qual são indicadas as sequências discursivas que serão coerentes com o discurso em curso. Nessa perspectiva, o sentido de uma expressão, tratamento hormonal ou castração química, é um "encadeamento argumentativo" que indica os discursos posteriores possíveis, aqueles que se pode fazer a partir dessas expressões.

Essa teoria coloca, de fato, a argumentação não somente nos enunciados, mas também nos termos que os constituem, de modo que toda expressão linguística provida de um sentido é parafraseável por uma argumentação (ou por um conjunto de argumentações). Por exemplo, a palavra prudente tem, em sua significação, uma argumentação do tipo PERIGO PORTANTO TOMAR PRECAUÇÕES; essa sequência de palavras constitui a "argumentação interna" de prudente, ela resume o que se passa no interior dessa palavra. Assim, quando um locutor diz de Pedro que ele foi prudente, ele comunica a argumentação: havia perigo portanto Pedro tomou precauções. Ele mostra Pedro como tendo tomado precauções por causa do perigo. Além disso, a palavra prudente tem igualmente em sua significação outros esquemas argumentativos, como a alternativa: PRUDÊNCIA PORTANTO SEGURANÇA/ PRUDÊNCIA NO ENTANTO NÃO SEGURANÇA. Essas duas sequências argumentativas constituem a "argumentação externa" de prudente, elas indicam quais encadeamentos discursivos são possíveis a partir dessa palavra. Assim, pelo enunciado "Pedro foi prudente", o interlocutor pode compreender que Pedro estava seguro, por causa de sua prudência (Pedro foi prudente, portanto ele esteva seguro), ou que ele não estava seguro, apesar de sua prudência (Pedro foi prudente no entanto ele não estava seguro).

$\mathrm{Na}$ semântica argumentativa que a Teoria dos Blocos Semânticos propõe, a significação de uma expressão é, portanto, descrita por argumentações (internas e externas). Empregando uma palavra para descrever uma situação, apelamos para as argumentações inscritas em sua significação, exercemos uma ação sobre nosso ouvinte, indicando-lhe as sequências discursivas coerentes com o discurso em curso. É nesse sentido que Pierre-Yves Raccah (2002) diz do léxico que ele é "ideológico": as palavras escolhidas pelo locutor obrigam o interlocutor a adotar um certo ponto de vista, o ponto de vista argumentativo expresso pelo entrelaçamento dessas palavras; sem isso, ele não pode interpretar o sentido do enunciado, e consequentemente, responder. Nessa perspectiva, as expressões castração química e tratamento hormonal exprimiriam argumentações diferentes; elas se distinguiriam pelo ponto de vista que exprimem, pelo movimento argumentativo com o qual pressionam o ouvinte.

$\mathrm{Na}$ primeira parte, dirigiremos nossa atenção para o tempo em que o emprego dessas expressões revela uma adesão ou uma rejeição a essa técnica médica, tempo que chamaremos "tempo 1". Estabeleceremos a significação 
argumentativa dessas duas expressões, dito de outro modo, as argumentações que as resumem (sua argumentação interna), assim como as sequências discursivas que elas tornam possíveis (suas argumentações externas). Tratar-se-á de saber se o poder ofensivo da expressão castração química reside em sua significação (isto é, nas argumentações que ela exprime) ou em seu emprego (isto é, no modo como o locutor põe em cena essa palavra em seu enunciado). Depois de ter confrontado essas duas expressões, veremos que, efetivamente, é a significação de castração que o oponente mobiliza para denunciar essa técnica; é porque a própria palavra causa medo que seu emprego pode ser ofensivo. Numa segunda parte, vamos nos interessar pelo tempo em que os oponentes, tanto quanto os partidários, utilizam a expressão castração química, tempo que chamaremos "tempo 2". Tratarse-á de determinar as razões pelas quais os partidários começaram a empregá-la. Essa expressão teria se tornado inofensiva? Teria sido o significado da palavra castração que mudou, ou é o modo como ela é usada? Na realidade, essa expressão perderia um pouco de seu poder, em razão do fato de que ela é contrastada com outra expressão: castração fisica. O aparecimento dessa nova expressão constrói então um novo uso de castração química, um uso partidário, ofensivo a seu modo. Por que, de fato, os partidários a empregariam, a não ser para causar medo, já que a expressão tratamento hormonal é mais apropriada à técnica que eles defendem, conforme confissão até mesmo dos oponentes?

\section{Tempo 1: quando castração química se opõe a tratamento hormonal}

O "tempo 1" corresponde ao tempo em que a expressão castração química é unicamente empregada pelos oponentes, para um emprego dessa expressão no qual é primeiramente a palavra castração que se ouve. Seguindo a terminologia da Teoria dos Blocos Semânticos, diremos que a expressão castração química está "centrada" na palavra castração e que o adjetivo química não intervém em sua significação, que ele é "anedótico": é preciso ver como uma espécie de complemento circunstancial, como algo não necessário para a compreensão do enunciado. Essa teoria distingue, efetivamente, a presença de uma palavra em um enunciado, do papel que ela representa. Não é porque uma palavra está materialmente presente que ela traz seu sentido; só as palavras argumentativamente pertinentes participam do sentido do enunciado (CAREL, 2009).

Entretanto, pode ser difícil aceitar a ideia segundo a qual podemos não levar em conta certas palavras para construir o sentido de um enunciado, porque nós os julgamos "anedóticos" de um ponto de vista argumentativo. Assim, observemos o exemplo seguinte. No enunciado "Pedro é prudente", o nome próprio Pedro é argumentativamente não pertinente, isto é, o locutor pode substituí-lo pela expressão fulano sem que o sentido do enunciado fique comprometido. O enunciado "Fulano é prudente" continua, de fato, compreensível. Por outro lado, não se pode substituir prudente pelo termo coisa sem perder, ao mesmo tempo, o sentido do enunciado, "Pedro é coisa" sendo dificilmente compreensível. O sentido do enunciado é assim centrado em prudente. Do mesmo modo, no tempo 1, no primeiro emprego que é feito de castração química, o sentido é centrado em castração. Se os oponentes que utilizam essa expressão suprimissem o adjetivo química e só empregassem o substantivo castração, eles não perderiam o efeito discursivo esperado (dar medo), enquanto que eles não poderiam suprimir castração e só utilizar química sem perder esse efeito. Observemos os diálogos seguintes: o primeiro é centrado em castração e o segundo em química:

(1) - Você viu o que eles querem fazer com os delinquentes sexuais?

- Sim... Eles querem castrá-los. Como é mesmo que eles chamam isso? A castração...?

- A castração química.

(2) - Você viu o que eles querem fazer com os delinquentes sexuais?

- Sim, eles querem que eles façam um tratamento. Como é mesmo que eles chamam isso? $\mathrm{O}$... uma coisa química?

- A castração química.

\subsection{Argumentação interna de castração}

O emprego oposto de castração química estando centrado na palavra castração, o que comunica esse último? Por que os opositores o escolheram? Trata-se, portanto, de estabelecer sua significação argumentativa, a saber, sua argumentação interna; será necessário encontrar uma sequência argumentativa que distinga a palavra castração das palavras abstinência ou esterilidade, e que dê conta da violência associada à ideia de castração. Inicialmente vamos dirigir nossa atenção para as definições que diferentes dicionários deram à palavra castração:

- Dictionnaire de l'Académie française, $4^{\mathrm{a}}$ edição, 1762: "Termo de Cirurgia. Operação pela qual se castra um homem, um animal"

- Littré, 1877: “Termo de cirurgia. Operação pela qual se castra um homem, um animal [...] Os cirurgiões denominam também castração a retirada de um dos testículos afetados por tumor: daí a distinção entre castração completa e incompleta." 
- Grand Larousse de la langue française, 1971: "Retirada total ou unilateral das glândulas genitais em indivíduo masculino ou feminino."

- Dictionnaire de l'Académie française, 9 $9^{\mathrm{a}}$ edição, 1992: "Operação pela qual são suprimidas as glândulas genitais em um homem ou em uma mulher, destruindo assim essas faculdades de reprodução. $A$ castração, pode ser cirúrgica ou produzida por certas radiações".

- Petit Robert 2000-2010: "Operação pela qual priva-se um indivíduo, homem ou mulher, da faculdade de se reproduzir (esterilização; castrar). Castração radiológica, por irradiação das gônadas. Castração por retirada dos testículos (emasculação), dos dos ovários (ovariectomia)."

A castração está associada a uma operação que visa à destruição dos órgãos sexuais ${ }^{3}$; encontra-se, de fato, nessas diferentes definições, os termos cirurgia, ablação, supressão, destruição... Como confirma o exemplo seguinte: em 1997, nos Estados Unidos, houve o suicídio coletivo de 39 membros da seita "As portas do paraíso" de Rancho Santa Fé. Na televisão, podíamos ouvir isso: "As autópsias praticadas em cadáveres permitiram perceber que certo número de adeptos masculinos se fizeram castrar, dos quais o próprio guru que pregava abstinência sexual", ou ainda, "Revelação cada vez mais surpreendente, alguns desses homens tinham sofrido uma retirada dos testículos"4. Assim, eu formalizo a argumentação que resume o que se passa na palavra castração (isto é, a argumentação interna) pelo predicado argumentativo: ÓRGÃOS SEXUAIS NO ENTANTO SUPRIMIDOS. Quando eu digo que mandei castrar meu gato, eu digo que apesar de que meu gato tivesse tido órgãos sexuais, eu os fiz cortar. Entretanto, para dar conta do aspecto definitivo ligado a essa operação, corrigiremos um pouco essa argumentação, e substituiremos os termos cortados ou desparecidos pelo termo destruídos: ÓRGÃOS SEXUAIS NO ENTANTO DESTRUIIDOS.

Do mesmo modo, empregar a noção castração química de preferência a tratamento hormonal, é dar a entender a técnica que visa inibir as funções sexuais como uma destruição dos órgãos sexuais. $\mathrm{O}$ que não é o caso de tratamento hormonal. De acordo com a definição dada pelo dicionário ATILF para a palavra tratamento (cf. "Medicina. Ação de cuidar de um doente de modo continuado. Por metonímia: conjunto dos meios apropriados destinados a prevenir uma doença, ou a curar um doente."), tal expressão evoca uma argumentação do tipo DOENTE PORTANTO CUIDADO (DURANTE CERTO TEMPO). O fato de que castração química apareça como uma expressão violenta e própria a dar medo, enquanto não é o caso de tratamento hormonal, provém, portanto, em parte, de sua argumentação interna, em que cada uma delas se inscreve em campos semânticos diferentes. A expressão tratamento hormonal remete à ideia de cuidado, ela é utilizada para outros casos distintos de prevenção da recidiva sexual, casos tais como o câncer ou a menopausa, nos quais ela toma um valor positivo, já que ela subentende as ideias de cura ou de estar melhor fisicamente. Ao contrário, a expressão castração química - aplicada ao ser humano - é conotada negativamente, porque ela remete às ideias de mutilação, de práticas indignas ou bárbaras etc. A castração se opõe, então, ao tratamento hormonal do mesmo modo que um ato de destruição se opõe a um ato de cura.

\subsection{Outras argumentações inscritas na significação de castração}

Nós descrevemos a expressão castração química considerando que química era anedótica e que a violência que ela exprimia repousava na palavra castração. Ora, a castração química é uma castração tal como nós a entendemos habitualmente? Não, e aqueles que a empregam com o objetivo de causar medo, sabem bem disso. No blog de um juiz, oposto ao projeto de lei, podemos ler isto ${ }^{5}$ :

Pondo em prática a doutrina de agora em diante bem instalada 'Uma crônica policial - uma lei', o governo relançou ultimamente a ideia da 'castração química' para certos condenados que cometeram infrações sexuais. Assinalaremos imediatamente que a expressão empregada é absurda e de natureza a enganar a opinião pública. De fato, a 'castração' é a extirpação de um órgão genital necessário à reprodução, o que não tem nada a ver com tratamento médico destinado a reduzir a libido. Mas essa expressão 'castração química', até mesmo deliberadamente enganadora, é sem dúvida midiaticamente eficiente... ${ }^{6}$

Como a expressão castração química pode ser midiaticamente mais eficaz do que tratamento hormonal, enquanto ela não é apropriada à situação que se considera que ela designa? A ideia de castração é associada a um ato de destruição, a uma supressão definitiva dos órgãos sexuais, de modo que a expressão castração química

\footnotetext{
Escolheremos a expressão "órgãos sexuais" de preferência a "órgãos de reprodução" porque, nessa expressão, trata-se antes de impedir o ato sexual do que da capacidade de gerar filhos. É nesse sentido que se poderia empregar o qualificativo castrada para uma mulher, enquanto seria estranho fazer isso para uma mulher a quem foram retirados os ovários.

4 Arquivos INA, de 29/03/1997, midi 2, ina.fr

5 Esse exemplo autoriza várias leituras; eu me concentro naquela que opõe "castração química" a "tratamento hormonal" mais do que naquela que opõe "reprodutivo" a "sexual".

6 La "castração química", étude de législation comparée. Paroles de juges, Michel Huyette, 29/11/09, huyette.net
} 
apresenta essa técnica como uma operação irreversível. A noção de tratamento, ao contrário, dá a entender que a suspensão deste permitiria aos órgãos sexuais funcionar novamente, que a diminuição da libido por meio de medicamentos é reversível, como lembra um partidário, o emprego da expressão castração química é, portanto, impróprio:

Um estudo do Inserm [...] deve estudar, em voluntários sadios de 18 a 60 anos, o efeito de dois medicamentos que acarretam uma baixa da libido. Precisemos que não pode se tratar de "castração química", um termo sem significação porque o efeito dos medicamentos é reversível logo de sua suspensão. ${ }^{7}$

De fato, as expressões castração química e tratamento hormonal inscreveram em sua significação, no nível de suas argumentações externas, as ideias de irreversibilidade e reversibilidade. Elas podem dar lugar às sequências discursivas seguintes (dentre outras): CASTRAÇÃO PORTANTO NÃO REVERSÍVEL para a primeira e TRATAMENTO HORMONAL PORTANTO REVERSÍVEL para a segunda. Para que possamos comparar as duas expressões mais facilmente, transformaremos essas duas argumentações de modo que elas ponham em jogo os mesmos elementos e possam assim ser comparadas. A ato medicamentoso será considerado como um não ato cirúrgico, ou melhor, como uma não destruição. Assim, temos como argumentação externa de castração: ATO CIRÚRGICO PORTANTO NÃO REVERSÍVEL ou, modificada, DESTRUIÇÃO PORTANTO NÃO REVERSÍVEL, e como argumentação externa de tratamento: NÃO ATO CIRÚRGICO PORTANTO REVERSÍVEL ou, modificada, NÃO DESTRUIÇÃO PORTANTO REVERSÍVEL.

É o caráter irreversível da castração que torna a expressão castração química própria a causar medo: o fato de que essa operação seja irreversível pode, de fato, ser considerado como uma mutilação, isto é, como um ato contrário à dignidade humana. De fato, a castração tiraria do homem o que faz dele um homem e se ouviria essa outra argumentação: ERA UM HOMEM NO ENTANTO NÃO É MAIS UM HOMEM. Enquanto a expressão tratamento hormonal, pelo fato de que ela remete a uma operação que não é irreversível, daria antes a entender uma argumentação tal como: É UM HOMEM NO ENTANTO NÃO É UM HOMEM ATUALMENTE. Se esse homem não é um homem atualmente, não é porque ele foi mutilado, mas porque ele está em tratamento.

Nesse sentido, pode-se igualmente pensar no empego simbólico que é feito da palavra castração, do mesmo

\footnotetext{
A "castração química", por antiandrógenos sempre em estudo, 14/10/07. Lefigaro,fr
}

modo que com o qualificativo castradora atribuído a uma mulher, quando ela toma do homem o que faz dele um homem, e mais precisamente, no exemplo seguinte, quando ela se atribui o poder de decisão. São duas cenas extraídas da série televisiva Desperate Housewives de Marc Cherry (Estação 6, episódio 5):

\section{Cena 1}

Lynette: Por que você telefonou para o Tom?

Roy: Eu queria ter certeza de que ele não tinha nada contra o lugar em que você quer pendurar essa gaiola, porque é ele o homem da casa.

Lynette: Ok, entendo, como você utiliza um celular, você sabe em que século vivemos. Então, só para esclarecer as coisas, é inútil verificar tudo assim com o Tom, assim, eu tomo o máximo de decisões em nossa casa.

Roy: Eu tinha notado isso, digamos que eu prefiro tratá-lo com um pouco de respeito.

Lynette: Desculpa.

Roy: Você esmaga a masculinidade dele como se esmaga uma noz. Sente-se que agrada a você fazer isso, mas quanto a mim, não é meu jeito.

Lynette: Mas sem querer contrariar você, as nozes dele são o que há de mais intacto, e você quer que eu lhe diga? Creio que paramos por aqui. Eu não o prendo mais.

\section{Cena 2}

Tom: Eu confesso que não consigo entender por que tu dispensaste Roy. Tanto mais que ele estava pronto para pôr essa detestável gaiola onde tu querias.

Lynette: Não, não tem nada a ver com isso. Ele ousou dizer que eu te castrava, te dás conta?

Tom: Ele disse isso?

Lynette: Bom, não foi a palavra que ele usou, ele se mostrou mais pitoresco fazendo referência ao quebra-nozes.

Tom: (risos) Ele é engraçado.

Lynette: Mas ele não é engraçado! É justamente aí que tu deverias intervir dizendo que eu não sou a odiosa castradora que ele imagina!

Tom: De acordo. Antes, tu largas a faca.

Lynette: ... (contrariada)

Tom: Uau!... não te faz rir, essa história!

\section{Tempo 2: quando castração química não se opõe mais a tratamento hormonal mas a castração física}

O "tempo 2" remete ao tempo em que não são mais somente os opositores que empregam a expressão castração química, mas igualmente os partidários; tratase, portanto, de saber se o fato de que os partidários empregam agora essa expressão significa que ela não causa mais medo. Vamos ver que esse novo emprego 
provém do aparecimento de uma nova expressão: castração física, a qual modifica o sentido de castração química, porque quando o adjetivo química é confrontado a física, a violência da palavra castração, em castração química, parece atenuada. O termo química enfraqueceria e talvez mesmo negaria o sentido de castração, enquanto fisica reforçaria.

De fato, no que chamamos "tempo 1", o adjetivo química era anedótico de um ponto de vista argumentativo, ele não participava do sentido do enunciado, ele não tinha nenhum papel preciso e não influenciava o sentido de castração. O locutor, oponente, que empregava a expressão castração química queria primeiramente dar a entender a palavra castração e usar de seu poder para causar medo. No que chamamos de "tempo 2", o adjetivo química torna-se um "operador", isto é, um termo que age sobre a significação da palavra à qual ele é associado, ou que obriga a escolher certas argumentações dentre as argumentações inscritas na significação dessa palavra. O aparecimento da expressão castração física teria então por vocação dar a entender o qualificativo química na expressão castração química, de torná-lo argumentativamente pertinente. De modo que o locutor partidário, que emprega essa expressão, insiste agora na palavra química e faz representar um papel.

Segundo a semântica argumentativa, os termos química e física são operadores que agem sobre o sentido do termo castração ao qual eles são associados. Sobre o que eles agem? Eles modificam a argumentação interna de castração? e/ou sua argumentação externa? Duas hipóteses podem ser de fato levantadas quanto à mudança de sentido da expressão castração química, pelo fato do aparecimento de uma nova expressão castração física: a primeira hipótese (a) seria que a significação de castração se modificou na língua, isto é, que teria havido uma mudança da argumentação interna; a segunda (b) seria que os adjetivos química e física agem sobre a significação de castração no nível discursivo, mantendo sua significação na língua. Manteremos essa segunda hipótese, aquela na qual o termo química é um operador que tem por função enfraquecer, até mesmo negar, o termo castração. Então, a ação do operador química tem sobre a argumentação interna de castração química consequências sobre a argumentação externa, consequências que poderiam explicar por que os partidários empregam agora essa expressão.

\subsection{Ação de química sobre a argumentação interna de castração}

HIPÓTESE (a) - O aparecimento da expressão castração física teria como consequência modificar a definição da palavra castração, isto é, sua significação, tal como está inscrita na língua. De fato, se devêssemos considerar que uma castração química é de fato uma castração, seria necessário passar da ideia original de destruição à mais moderna de suspensão, de parada. Tal modificação poderia, aliás, corresponder a uma mudança na definição de castração que podemos observar nos dicionários mais recentes. Olhando essas definições mais de perto, podemos ver de fato que a ideia de ato cirúrgico ou de ato radiológico, subentendendo a ideia de destruição, é abandonada em benefício de uma ideia mais abstrata: com o termo privar, a castração é entendida como um ato de privação, de supressão. A expressão castração química modificaria, então, a argumentação interna original de castração (ÓRGÃOS SEXUAIS NO ENTANTO DESTRUÍDOS) e lhe daria uma forma menos violenta: ÓRGÃOS SEXUAIS NO ENTANTO SUPRIMIDOS, PARADOS, DESATIVADOS... Ora, o sentimento de que o qualificativo química enfraquece a palavra castração, enquanto fisica a reforça, provém desse enfraquecimento no modo como é formulada a definição de castração? Além disso, se aceitássemos essa hipótese, deveríamos então dizer que a expressão castração física remete à antiga significação de castração, sob sua forma violenta? Uma segunda hipótese pode, entretanto, ser proposta.

HiPÓTESE (b) - Seria possível, de fato, considerar que os operadores química e física são, respectivamente, "modificadores desrealizantes e realizantes" (DUCROT, 1995). Esse tipo de operador é construído sobre o modelo das palavras pouco, um pouco e muito que têm, cada uma, uma ação diferente sobre a palavra à qual elas estão ligadas. Por exemplo, à pergunta "Pedro comeu?", a resposta "Pedro comeu muito" reforça a argumentação interna de comer; muito realiza comer. A resposta "Pedro comeu um pouco" comunica a ideia de que Pedro comeu, mesmo se foi pouco, enquanto a resposta "Pedro comeu pouco" comunica a ideia de que Pedro não comeu verdadeiramente. No primeiro caso, um pouco atenua o verbo comer, isto é, a argumentação inscrita na significação de comer é mantida até mesmo se ela é tornada menos forte, enquanto no segundo caso, pouco atenua tanto comer que o inverte, isto é, que a argumentação inscrita na significação de comer é transformada em seu contrário, não comer. Seguindo o modelo de um pouco, química seria um desrealizante atenuador, dito de outro modo, ele diminuiria a orientação argumentativa de castração, mantendo-a; e seguindo o modelo de pouco, o qualificativo química desrealizaria tanto castração quanto inverteria sua argumentação: ser castrado quimicamente seria não ser verdadeiramente castrado. A expressão castração química teria então uma argumentação interna contrária à de castração física, que seria, em decorrência, ser verdadeiramente castrado. 
Efetivamente, a expressão castração física comunica que se trata de uma verdadeira castração, física realiza castração, ela reforça sua argumentação interna, ÓRGÃOS SEXUAIS NO ENTANTO DESTRUÍDOS. Como mostra o exemplo a seguir: "O violador presumido de Enis pede a castração física. Francis Evrard escreveu uma carta a Nicolas Sarkozy para pedir-lhe que autorizasse uma supressão dos testículos por cirurgia". ${ }^{8}$

A expressão castração química comunica, quanto a ela, que não se trata de fato de uma castração; química desrealiza tanto castração que inverte sua argumentação, ela evoca, então, a argumentação contrária de castração, a saber: ÓRGÃOS SEXUAIS PORTANTO NÃO DESTRUÍDOS. Essa expressão teria, assim, a mesma argumentação que tratamento hormonal, já que essa expressão, como não destruição, evoca igualmente essa argumentação.

\subsection{Ação de química sobre as argumentações externas}

O aparecimento da expressão castração física torna, portanto, as expressões castração química e tratamento hormonal equivalentes de um ponto de vista argumentativo, já que elas evocam agora a mesma argumentação interna, mas isso não é tudo, o operador química, por oposição a física, modifica igualmente o caráter não reversível de castração. A ação desses operadores leva a selecionar, para cada uma dessas expressões, argumentações externas diferentes. No "tempo 1", a expressão castração química era associada à argumentação DESTRUIÇÃO PORTANTO NÃO REVERSÍVEL, enquanto tratamento hormonal era associado à argumentação NÃO DESTRUIÇÃO PORTANTO REVERSÍVEL. No "tempo 2", é agora a expressão castração fisicica que é associada à argumentação DESTRUIÇÃO PORTANTO NÃO REVERSÍVEL, enquanto castração química é associada a NÃO DESTRUIÇÃO PORTANTO REVERSÍVEL.

A castração química é o quê mesmo? É um tratamento hormonal que reduz a produção de testosterona e diminui de fato a libido. $\mathrm{O}$ tratamento não impede as relações sexuais, mas torna-as muito menos frequentes. Ele reduz sobretudo as pulsões sexuais. [...] Contrariamente à castração cirúrgica, a castração química não é irreversível. É um tratamento prescrito por um médico, compreendendo comprimidos para engolir a cada dia e de uma injeção (todos os meses ou a cada três meses, conforme o medicamento). Ele é acompanhado sempre de um enquadramento social importante e principalmente psicológico. ${ }^{9}$

Assim, a expressão castração química torna-se o estrito equivalente - de um ponto de vista argumentativo - da expressão tratamento hormonal, já que elas exprimem agora as mesmas argumentações (internas e externas). No “tempo 1", vimos que a violência da expressão castração química provinha de seu caráter irreversível. Como mutilação contrária à dignidade humana, essa expressão subentendia a argumentação: ERA UM HOMEM NO ENTANTO NÃO É MAIS UM HOMEM. No "tempo 2", é agora a expressão castração física que subentende essa argumentação:

A castração física, por supressão dos testículos, não existe na França, porque é 'contrária à dignidade humana'. Só a castração química por tratamento hormonal, que é reversível, é possível, a pedido do paciente. ${ }^{10}$

A expressão castração química, quanto a ela, como operação não irreversível, subentende agora a mesma argumentação que a expressão tratamento hormonal, a saber: É UM HOMEM NO ENTANTO NÃO É UM HOMEM ATUALMENTE. Como anteriormente, se não é um homem atualmente não é porque foi mutilado, mas porque ele está em tratamento - conforme a nova argumentação interna ÓRGÃOS SEXUAIS PORTANTO NÃO DESTRUÍDOS, segundo a qual, ele não está verdadeiramente castrado.

\section{Conclusão}

Este estudo procurava saber se a violência de uma palavra vinha de sua significação ou de seu emprego; observando a evolução da expressão castração química, do "tempo1" ao "tempo2", podemos concluir que a violência associada a essa expressão provém da significação de castração mas igualmente do modo como essa palavra é empregada com os adjetivos química e fisica, isto é, do papel que o locutor a faz desempenhar em seu enunciado. No "tempo 1", o locutor que emprega essa expressão centraliza seu enunciado na palavra castração; química é anedótica de um ponto de vista argumentativo. O ouvinte é, portanto conduzido a ver na operação que visa a diminuir a libido, um ato de mutilação, contrário à dignidade humana. O medo que essa expressão provoca vem, então, da significação da palavra castração sobre a qual o oponente centraliza o emprego dessa expressão. No "tempo 2", o locutor partidário que emprega essa expressão, insiste em química; ele lhe dá um papel no enunciado, o de um operador que desrealiza a palavra castração, dito de outro modo, negando-a. Essa ação

\footnotetext{
8 O violador presumido de Enis pede a castração física, 17/10/09, Libération.fr

9 Castration chimique: état des lieux, 02/10/09, Libération.fr

${ }^{10}$ Le violeur présumé du petit Enis demande à être castré, 17/10/09. Le Figaro.fr
} 
de química provém do fato de ser colocada com outra expressão castração física, na qual o operador física realiza a palavra castração, reforça-a. Assim, o sentido de castração química é modificado e tornado equivalente ao de tratamento hormonal. A castração química não sendo mais considerada como uma verdadeira castração, a argumentação que ela evoca é agora a de não castração; em consequência do quê, a ação que visa diminuir a libido não é mais percebida pelo ouvinte como um ato de mutilação, contrário à dignidade humana, porque é agora a expressão castração física que herda a violência da palavra castração.

Todavia, notar-se-á que a aparência agora inofensiva de castração química não impede que essa expressão seja escrita entre aspas. A reticência em empregar essa expressão viria do fato de que essa expressão continua a dar medo? Seria também porque ela não é correta, isto é, não apropriada ao que ela deve designar? Por que empregar a expressão castração química enquanto que a expressão tratamento hormonal é inofensiva e finalmente adequada? Qual é o efeito retórico que explicaria seu emprego para os partidários dessa técnica?

A expressão castração química tendo sempre dois sentidos (o do "tempo 1" e o de "tempo 2"), o emprego de castração química mais do que o de tratamento hormonal permitira ao locutor partidário jogar com um quadro duplo: fazendo ouvir a palavra castração, o locutor mostra que ele não tem medo das palavras, e apela para o sentido 1 de castração química (correspondente ao "tempo 1") que, por seu aspecto brutal, dá a ilusão de que o perigo encartado pelos delinquentes sexuais está definitivamente afastado. Aqueles sendo mostrados como castrados, suas perigosas pulsões seriam não suspensas, mas destruídas, e isso, de modo irreversível. Mas, como vimos, a castração química, não sendo uma verdadeira castração, o locutor pode se apresentar respeitando, do mesmo modo, a dignidade humana, apelando, então, para o sentido 2 de castração química (correspondente ao "tempo2"). Destinando àqueles que teriam medo das palavras, o locutor pode assim comunicar a ideia de que a técnica aplicada aos delinquentes sexuais não os mutila, trata-os: a castração química não é uma castração física, ela é um tratamento. Em conclusão, empregando essa expressão, os partidários dessa técnica conservam a ideia de irreversibilidade da castração, fazendo da criminalidade sexual um problema resolvido e, ao mesmo tempo, eles se apresentam como respeitosos da dignidade humana, preparando assim os ataques dos oponentes, que empregavam essa expressão para denunciar a técnica mutiladora e indigna.

\section{Referências}

CAREL, Marion. Argumentation interne et argumentation externe au lexique: des propriétés différentes. Langages, Paris, n. 142, p. 11-21, 2001.

CAREL, Marion. L'ambivalence argumentative: la sousdétermination des énoncés par les phrases. In: ATAYAN, Vahram; PIRAZZINI, Daniela (Éds.). Argumentation: théorie - langue - discours. Francfort: Peter Lang, 2009. p. 123-142.

CAREL, Marion. L'entrelacement argumentatif: lexique, discours et blocs sémantiques. Paris: Champion, 2010.

DUCROT, Oswald. Le dire et le dit. Paris: Minuit, 1984.

DUCROT, Oswald. Les modificateurs déréalisants. Journal of Pragmatics, Amsterdam, n. 24, p. 145-165, 1995.

FREGE, G. Ecrits logiques et philosophiques. Paris: Seuil, 1971.

RACCAH, Pierre-Yves. Lexique et idéologie; les points de vue qui s'expriment avant qu'on ait parlé. In: CAREL, Marion (Éd.). Les facettes du dire: hommage à Oswald Ducrot. Paris: Kimé, 2002. p. 241-268.

Recebido: 30 de novembro 2014

Aprovado: 26 de janeiro de 2015

Contato: margot.salsmann@gmail.com 